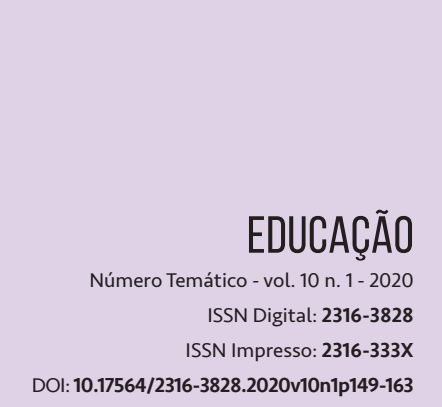

\section{LIVES, EDUCAÇ̃̃O E COVID-19: ESTRATÉGIAS DE INTERAÇÃO NA PANDEMIA}

LIVES, EDUCATION AND COVID-19:

INTERACTION STRATEGIES IN THE PANDEMIC

LIVES, EDUCACIÓN Y COVID-19: ESTRATEGIAS PARA LA INTERACCIÓN EN LA PANDEMAA
Beatriz Oliveira de Almeida ${ }^{1}$ Lynn Rosalina Gama Alves ${ }^{2}$

\section{RESUMO}

0 presente artigo apresenta um breve contexto do momento que estamos vivenciando no cenário escolar e acadêmico, frente a pandemia provocada pelo vírus SARS-CoV-2, que orientou pela suspensão das atividades de ensino na educação básica e superior pública, que por limitações técnicas e de infraestrutura impossibilitaram aos estudantes de realizarem atividades remotas. Nesse contexto, foi organizado o Congresso UFBA 2020, totalmente a distância, com a intenção de evidenciar as ações que continuam sendo realizadas apesar da suspensão das aulas. Para tanto, foram realizadas lives sobre diferentes temas, atendendo assim, distintos interesses da comunidade interna e externa. Assim, considerando o impacto deste evento, foi realizada uma investigação com o objetivo de analisar o nível de participação estabelecidas entre palestrantes/docentes e participantes de 3 mesas redondas realizadas no Congresso Virtual UFBA 2020, identificando as contribuições realizadas entre palestrantes-participantes e participantes-participantes. Após a análise dos eventos e as participações nos chats, podemos concluir que a interatividade tão desejada ficou comprometida pela quantidade de pessoas conectadas e as dificuldades dos docentes/pales- 
trantes de lidarem com diferentes canais de comunicação (chat, redes sociais, entre outros simultaneamente), para se comunicar com os participantes. Os resultados indicam também que as lives realizadas se constituíram em acervos importantes que poderão ser utilizados posteriormente, para promover aprofundamento dos assuntos apresentados, mas evidenciaram que no primeiro momento se constituíram em espaços de encontros para manter vivo o vínculo da universidade com os seus pares e comunidade interna e externa.

\section{PALAVRAS-CHAVE}

Lives. Educação. Covid-19. Comunicação.

\section{ABSTRACT}

This article presents a brief context of the moment that we are experiencing in the school and academic scenario, facing the pandemic caused by the SARS-CoV-2 virus, which guided the suspension of teaching activities in public basic and higher education, which due to technical and of infrastructure made it impossible for students to perform remote activities. In this context, the UFBA 2020 Congress was organized, totally at a distance, with the intention of highlighting the actions that continue to be carried out despite the suspension of classes. To this end, lives were held on diferente topics, thus serving different interests of the internal and external community. Thus, considering the impact of this event, an investigation was carried out in order to analyze the level of participation established between speakers/teachers and participants of 3 round tables held at the UFBA 2020 Virtual Congress, identifying the contributions made between speaker-participants and participants- participants. After analyzing the events and participating in the chats, we can conclude that the much desired interactivity was compromised by the number of people connected and the difficulties of teachers / speakers to deal with different communication channels (chat, social networks, among others simultaneously), to communicate with the participants. The results also indicate that the lives held were important collections that can be used later, to promote the deepening of the subjects presented, but showed that in the first moment they were spaces for meetings to keep the link between the university and its peers alive and internal and external community.

\section{KEYWORDS}

Lives. Education. Covid-19. Communication. 


\section{RESUMEN}

Este artículo presenta un breve contexto del momento que estamos experimentando en el escenario escolar y académico, frente a la pandemia causada por el virus SARS-CoV-2, que guio la suspensión de las actividades de enseñanza en educación pública básica y superior, que debido a de infraestructura hizo imposible que los estudiantes realizaran actividades remotas. En este contexto, el Congreso UFBA 2020 se organizó, totalmente a distancia, con la intención de destacar las acciones que se siguen llevando a cabo a pesar de la suspensión de clases. Con este fin, se llevaron a cabo emisiones en directo sobre diferentes temas, sirviendo así a diferentes intereses de la comunidad interna y externa. Por lo tanto, considerando el impacto de este evento, se llevó a cabo una investigación para analizar el nivel de participación establecido entre oradores/ profesores y participantes de 3 mesas redondas celebradas en el Congreso Virtual UFBA 2020, identificando las contribuciones realizadas entre oradores/profesores y participantes. Después de analizar los eventos y participar en los chats, podemos concluir que la interactividad tan deseada se vio comprometida por la cantidad de personas conectadas y las dificultades de los profesores/oradores para lidiar con diferentes canales de comunicación (chat, redes sociales, entre otros simultáneamente), para comunicarse con los participantes. Los resultados también indican que las emisiones en directo celebradas eran colecciones importantes que podrían usarse más adelante, para promover una comprensión más profunda de los problemas presentados, pero mostraron que en el primer momento eran espacios para reuniones para mantener vivo el vínculo entre la universidad y sus pares, comunidad interna y externa.

\section{PALABRAS CLAVE}

Emisiones en directo; Educación; Covid-19; Comunicación.

\section{INTRODUÇ̧̃̃O}

O contexto do cenário mundial vem apresentando um momento atípico para a humanidade, pois a partir de dezembro de 2019, estamos enfrentando os efeitos nefastos da pandemia causada pelo vírus SARS-CoV-2, responsável pela enfermidade da COVID-19, exigindo medidas de isolamento e distanciamento social que atingiram diferentes setores da sociedade, destacando as instituições de ensino nos diferentes níveis.

Assim, professores e estudantes no mundo todo, tiveram as suas dinâmicas de processos de ensino e aprendizagem afetados, mobilizando no Brasil, a publicação de documentos oficiais, a exemplo das Portarias 343, 345, 356 (estas substituem a 342) e 473 (BRASIL, 2020a, 2020b, 2020c, 2020d) que orientaram as práticas pedagógicas nesse momento. 
Tais documentos provocaram, especialmente, as instituições privadas a adotarem práticas que vêm sendo denominadas de Ensino Remoto, que se diferencia da Educação a Distância por ser uma alternativa emergencial, na qual os docentes realizam as suas atividades em tempo real, isto é, encontros mediados por plataformas virtuais, nos horários que ocorriam as aulas presenciais, com o mesmo tempo de duração, adaptando os materiais que já usavam para esse novo formato. Entretanto, os professores não foram preparados para este modelo e, muitas vezes, não possuem habilidades de letramento digital para interagirem nos distintos ambientes virtuais, articulando os conteúdos escolares/acadêmicos, gerando um grande desgaste físico e mental dos atores do processo de ensinar e aprender.

Devido ao fechamento das escolas durante a pandemia, uma parcela significativa da população sofre os impactos na sua saúde psíquica. Neste grupo, podemos afirmar que os docentes, especialmente aqueles vinculados à rede privada, como dito anteriormente, se encontram em um estado de esgotamento físico e mental oriundo das atividades remotas, comprometendo a saúde psíquica, inclusive contribuindo para o problema da depressão, considerada pela Organização Mundial de Saúde (OMS), como uma epidemia mundial (OMS, 2020).

Os docentes da rede pública não estão realizando suas atividades de ensino por meio da Educação Remota por conta da ausência de infraestrutura técnica e de espaços adequados em casa para participar de tais práticas, seja por parte dos seus alunos, seja por parte dos próprios professores, que por questões socioeconômicas e culturais são excluídos do mundo digital. Contudo, também apresentam questões de esgotamento físico e mental diante do atual cenário, inclusive pela indefinição do que será feito em relação ao retorno das atividades docentes devido aos aspectos indicados anteriormente.

Nessa circunstância, a Universidade Federal da Bahia (UFBA) vem adotando ações junto com sua comunidade acadêmica, em busca de alternativas para manter suas práticas de ensino, pesquisa e extensão de qualidade e comprometida com o atendimento aos seus discentes, incluindo-os, amenizando as diferenças sociais, culturais e educacionais dos seus 40.879 alunos da graduação e 7.914 da pós-graduação.

Assim, destacamos que teremos como objeto de análise três lives que foram realizadas durante 0 primeiro Congresso Virtual da UFBA, no período de 18 a 29 de maio de 2020, com temáticas relacionadas com Pandemia, Educação e Tecnologia.

Para discutir esses aspectos, este artigo está dividido em 4 seções, além desta introdução e das reflexões finais. Na primeira seção, "Plataformas digitais: os novos cenários da aprendizagem em tempos de pandemia" discutimos as categorias teóricas que embasam a nossa discussão. Na segunda seção, intitulada "Congresso virtual: UFBA em movimento", apresentamos a estruturação do evento virtual realizado pela universidade.

Na terceira seção denominada Procedimentos investigativos, discutimos a abordagem qualitativa que norteou a pesquisa socializada neste artigo. Os resultados da pesquisa e a discussão serão analisados na quarta seção e finalmente, na conclusão apontamos trilhas que podem contribuir para delinear as práticas no ensino superior mediadas pelas plataformas digitais. 


\section{PLATAFORMAS DIGITAIS: OS NOVOS CENÁRIOS DA APRENDIZAGEM EM TEMPOS DE PANDEMIA}

Durante a pandemia observamos o crescimento do uso das plataformas digitais, tanto as utilizadas majoritariamente para entretenimento, como o Facebook ou o Instagram, quanto aquelas com fins educacionais, como Teams (Microsoft), Google Classroom, Google Met, Zoom, dentre outras.

Estas plataformas permitem interações on-line, como: conversar, compartilhar, comentar, namorar virtualmente, pesquisar, fazer compras, ouvir música, assistir vídeos etc., delineando a maneira como vivemos e como a sociedade é organizada. Estruturadas por dados e organizadas por meio de algoritmos, as plataformas são projetadas, fundamentalmente, para organizar interações entre usuários (VAN DIJCK; POELL; DE WAAL, 2018), controlando os seus dados e direcionando esses sujeitos a uma rede infinita de informação a partir de um descritor de busca inicial. Por exemplo, ao procurar em um site por um produto, os sujeitos passam a receber distintas informações sobre esse item e/ou afins.

Nesse contexto de consumo, as lives (vídeos ao-vivo produzidos por artistas, empresários, professores, pesquisadores e youtubers) se transformaram em verdadeiras vedetes da pandemia. Promovidas e disponibilizadas em diferentes plataformas, como o Instagram, o Facebook e o YouTube, as lives contemplam diferentes temáticas que vão desde a área de entretenimento e orientação para manter a saúde mental durante a pandemia, até formação profissional e acadêmica.

Com diferentes objetivos, o consumo das lives tem proporcionado o engajamento social dos sujeitos envolvidos no processo, sejam eles atores ou espectadores dessas produções. Esse engajamento vai desde a comunicação síncrona entre os participantes nos chats, até o compartilhamento e as curtidas que potencializam a visibilidade do conteúdo.

O Instagram, por exemplo, apresentou um crescimento de $70 \%$ no que se refere a realização de lives, tanto para transmissão como para consumo. 0 Facebook fez implementações na sua configuração para realização de tais atividades e, plataformas de streaming como a Netflix e Amazon, já chegaram a registrar um crescimento de $20 \%$ só no mês de março de 2020 , segundo dados da Business Insider (LESKIN, 2020)

Contudo, da euforia inicial de participar e estar em diferentes encontros com seus ídolos, sejam acadêmicos, artísticos, influenciadores digitais, vemos emergir um desgaste e cansaço. Cansaço, frente ao dilúvio de informações que são veiculadas e não conseguimos administrar cognitivamente e desgaste, pois a frequência de lives foi surpreendente, ocorrendo muitas vezes simultaneamente, na qual a audiência precisa escolher o que vai ouvir naquele momento e como hesita.

Silard (2020) levanta o seguinte questionamento: como sobreviver a quarentena sem se tornar um Zoombie? O termo Zoombie criado pelo autor é um mix de zumbi e Zoom - software de videoconferência que vem ganhando espaço no contexto do novo Coronavírus devido a necessidade de realizar atividades remotamente, inclusive as lives. Silard (2020) registra que delineou o termo após a maratona que sua esposa vivenciou de estar durante o tempo de oito horas em reuniões nesta plataforma. Silard aponta uma conclusão muito familiar para todos nós - qualquer coisa levada ao extremo pode resultar em uma disfunção doentia, impactando na saúde psíquica desta audiência que precisa estar conectado o tempo todo. 
Todavia, além da preocupação com o consumo excessivo de informações, ainda existem dois pontos que precisam ser destacados, o primeiro deles é que, as plataformas digitais precisam ser vistas como mercados multifacetados que funcionam por modelos de negócios, envolvendo a mercantilização de dados, serviços e bens dos usuários (VAN DIJCK; POELL; DE WAAL, 2018). A mercantilização dos dados dos usuários se tornou, portanto, o motor do capitalismo contemporâneo, nos levando ao segundo ponto, a privacidade e segurança desses usuários.

Uma série de problemas associados à segurança foram reportados nos últimos meses, retornando ao caso da plataforma Zoom, dentre eles podemos destacar: sites falsos do Zoom criados para distribuir malware (softwares nocivos que buscam causar danos e roubar informações privadas de maneira ilícita) nos dispositivos dos usuários; videoconferências invadidas por cibercriminosos com ataques agressivos, exibindo pornografia e ameaçando os participantes durante as conferências on-line; dados como e-mails e fotos de milhares de usuários foram vazadas, permitindo o acesso de desconhecidos (GERMANO, 2020).

Desta forma, apesar de estarem revolucionando os modos de conexão dentro do cenário de distanciamento físico e social imposto pelo novo Coronavírus, as lives também devem ser pensadas criticamente a partir de uma série de variáveis, para que não sejam ultrapassados os limites da saúde mental, do esgotamento físico e da privacidade neste "novo normal" que estamos vivendo.

\section{CONGRESSO VIRTUAL: UFBA EM MOVIMENTO}

Na pandemia causada pela COVID-19, a prioridade das universidades públicas tem sido garantir o acesso de todos os estudantes no processo de ensino-aprendizagem. Portanto, suspenderam as atividades presenciais e não implantaram o ensino remoto que as instituições privadas adotaram como medida emergencial.

Em consonância com essa perspectiva, a UFBA, na tentativa de manter os alunos e docentes em processo contínuo de formação, estabeleceu uma parceria com o Coursera até setembro de 2020, para que os sujeitos do processo de ensinar e aprender possam realizar os cursos de maneira gratuita ${ }^{2}$.

Além disso, a UFBA promoveu no período de 18 a 29 de maio de 2020, o primeiro Congresso Virtual da instituição. Com o tema: “UFBA: Universidade em movimento", o evento teve o objetivo de se manter próximo da comunidade interna e externa, promovendo a reflexão científica, o intercâmbio e a discussão em tempos de pandemia. Importante é que, apesar das dificuldades enfrentadas pelas universidades públicas no Brasil, a UFBA não se ausentou do debate em torno da importância da educação de qualidade, diminuindo as diferenças sociais e culturais.

Todo o material do Congresso Virtual UFBA 2020 está disponibilizado no acervo do canal TV $U_{\text {UBA }}^{3}$ no YouTube. 0 evento contou com mais de 38 mil inscritos, entre docentes e discentes da

2 A comunicação foi feita por meio do e-mail institucional para alunos e professores no mês de maio de 2020 .

30 canal TV UFBA foi criado em 2010 e já possui mais de 30 mil inscritos, sendo que 17,6 mil pessoas se inscreveram no período do congresso virtual realizado pela instituição. Link de acesso ao canal: https://www.youtube.com/user/ webtvufba/featured 
comunidade interna e externa da instituição, servidores técnico-administrativos e pesquisadores nacionais e internacionais (EDGAR DIGITAL, 2020). Toda a programação foi viabilizada por meio da Streamyard que é uma plataforma live streaming que transmite simultaneamente para Facebook, YouTube, Linkedin, Instagram, dentre outras. Antes e durante o evento toda a divulgação ocorreu nas redes sociais da universidade, com chamadas para atividades e continuidade das discussões nestes canais.

0 congresso ofereceu uma média de 40 lives por dia, exibidas de 8 h30 min às $20 \mathrm{~h} 30 \mathrm{~min}$. Além de atividades gravadas como conferências com pesquisadores, professores e intelectuais nacionais e internacionais; mesas redondas com a participação dos docentes da UFBA e convidados externos, que trouxeram discussões sobre distintos temas e foram disponibilizadas, simultaneamente, em nove salas nas plataformas de streaming; exposição de vídeo pôsteres dos alunos de graduação e pós-graduação, com apresentações de 5 minutos sobre as atividades de pesquisa que esses estudantes estão desenvolvendo, mesmo durante o cenário de distanciamento físico e social; intervenções artísticas objetivando a valorização da cultura local; e o projeto “UFBA mostra sua cara”, que buscou realizar a divulgação dos cursos de graduação da universidade e suas respectivas áreas de atuação, especialmente, para os estudantes da rede pública de educação básica (EDGAR DIGITAL, 2020). Criado um grande acervo/repositório imagético com a memória do congresso e suas contribuições no canal da instituição.

Paralelo a organização do evento indicado acima, a UFBA com o objetivo de conhecer o nível de acesso de seus estudantes, realizou uma pesquisa no mês de abril, indicando que $21,4 \%$ dos participantes da pesquisa em nível de graduação não possuem disponibilidade de acesso à internet (UFBA, 2020a). Entretanto, ainda assim, as atividades do Congresso Virtual conseguiram mobilizar mais de 10 mil estudantes inscritos.

Logo, a UFBA buscou por meio de uma série de plataformas digitais, ressignificar sua relação com o ensino, a pesquisa e a extensão, estreitando o distanciamento e criando cenários de aprendizagem em tempos de isolamento social. Essas ações sinalizam o compromisso da instituição com práticas democráticas para produção e acesso à informação de qualidade, sobre distintos temas, inclusive a educação em tempos de pandemia.

Assim, nesse contexto delineamos questão de investigação: Como foram estabelecidos os processos de interação entre os palestrantes e audiência das lives que discutiram educação - tecnologia e pandemia?

\section{PROCEDIMENTOS INVESTIGATIVOS}

A metodologia que norteou a pesquisa foi de base qualitativa e exploratória, com o objetivo de analisar o nível de participação estabelecidas entre palestrantes/docentes e participantes de 3 mesas redondas realizadas no Congresso Virtual UFBA 2020, identificando as contribuições realizadas entre palestrantes-participantes e participantes-participantes.

As 3 mesas foram escolhidas, priorizando temáticas em torno de questões associadas à educação, ensino de ciências e tecnologias digitais, todas com discussões que transversalizavam, 
também, a questão do contexto da pandemia. Cada live tinha a duração de 1 hora e 30 minutos e esse tempo deveria ser igualmente dividido entre as apresentações dos integrantes da mesa e o debate com os participantes ouvintes.

A live 1, intitulada "Formação de professores, educação online e democratização do acesso às redes" foi transmitida no YouTube às 13:30 do dia 21 de maio de 2020, com os professores Roberto Sidnei Macedo (UFBA), Edméa Oliveira dos Santos (UFRRJ) e Nelson de Lucca Pretto (UFBA), com a mediação da professora Alessandra Santos de Assis (UFBA). A mesa teve a duração de 01:31:56h, 584 curtidas, 552 participantes ao vivo e um total de 1135 comentários no chat da live. Os integrantes da mesa discutiram a necessidade de se democratizar o acesso a rede e de se repensar o currículo para que haja uma educação on-line que se afaste da educação a distância massiva de transposição de conteúdos fragmentados nas plataformas digitais (TV UFBA, 2020c).

A live 2, "Educação em ciências na Escola no contexto da pandemia: ações da Rede Educa UFBA", foi exibida no YouTube às 13:30 do dia 22 de maio de 2020, contou com a mediação da professora Andreia Maria Pereira de Oliveira (UFBA) e a participação dos professores Ecivaldo de Souza Matos (UFBA), Patrícia Fernanda de Oliveira Cabral (UFBA), Paloma Nascimento Santos (UFBA), Rejane Maria Lira da Silva (UFBA) e professora Jomara Fernandes (UFBA). A mesa teve a duração de 01:31:26h, 112 curtidas, 72 participantes ao vivo e um total de 181 comentários no chat da live. Os professores integrantes da mesa apresentaram as principais ações da Rede Educa UFBA para estimular a aprendizagem de Ciências nas escolas com projetos de formação inicial e continuada de professores, com o objetivo de melhorar a qualidade da educação básica (TV UFBA, 2020b).

A live 3, intitulada "A educação no Brasil em tempos de pandemia e a defesa da educação pública de qualidade em todos os níveis", transmitida pelo Youtube às 13:30 do dia 25 de Maio de 2020, teve a participação de Claudia Cristina Pinto Santos (Membro do Grupo de Estudo e Pesquisa em Educação do Campo - UFBA/FACED/GEPEC) e das professoras Jaqueline Moll (UFRGS) e Alessandra Santos de Assis (UFBA), sob a mediação do professor Penildon Silva Filho (UFBA). A apresentação teve a duração de 01:31:35h, 281 curtidas, 456 participantes ao vivo e um total de 456 comentários no chat da live. As professoras discutiram a necessidade de se considerar a realidade concreta das famílias, dos professores e das crianças para que seja garantida o acesso a uma educação pública de qualidade e democrática, para tanto, foram apresentadas uma série de marcos políticos que embasaram a discussão proposta (TV UFBA, 2020a).

Para a análise, foi realizada uma planilha onde classificamos os comentários nas seguintes categorias: identificação do participante, formação/atuação, considerações, solicitações, questionamentos, diálogo entre participantes, saudações, congratulações e considerações dos membros da mesa no chat. Estes pontos, foram escolhidos a fim de organizar especialmente, as distintas formas de interação escolhidas pelos participantes, identificando sua formação e aderência com o tema da live, para o processo de análise. 


\section{DA EUFORIA À INFORMAÇÃO - CONTRIBUIÇ̃̃ES DAS LIVESPARA OS PROCESSOS DE FORMAÇÃO}

O distanciamento físico social devido a COVID-19 vem exigindo que os atores da educação avancem e recriem os modos de interação com a comunidade acadêmica e científica. Nesse sentido, o primeiro Congresso Virtual da UFBA ofereceu, dentre outras atividades, mais de 400 lives que apresentaram, de maneira unânime, a preocupação da instituição com o debate de qualidade. Dentre as 3 lives analisadas neste artigo, foi possível reconhecer por meio dos elogios e agradecimentos dos participantes o papel fundamental dos profissionais da Superintendência de Tecnologia da Informação (STI) da UFBA que estavam remotamente engajados, garantindo a qualidade de transmissão do evento.

Além disso, a presença de convidados e participantes locais e não locais, a diversidade de temas discutidos nas atividades, a integração de distintas plataformas digitais, palestras com tradução em libras e o grande número de atividades, muitas delas simultâneas, criou a possibilidade de ampliação do alcance, chegando a 23 mil inscritos externos a comunidade da UFBA, demonstram, portanto, a repercussão e a relevância do evento para a sociedade.

Todavia, também foi possível identificar nas lives analisadas, um modelo baseado em uma perspectiva broadcasting, ou seja, alguns professores replicam a experiência presencial por meio da transmissão massiva de conteúdo, da leitura de textos longos e apresentação de slides com muito conteúdo, sem interação com a audiência. Essa prática demonstra que os participantes possuem uma dificuldade em se adequar à dinâmica do congresso on-line, desrespeitando o tempo de fala, o espaço dos outros integrantes da mesa e o debate com os participantes.

$\mathrm{Na}$ live 3, por exemplo, as professoras excederam o limite de tempo de fala, comprometendo o espaço para discussão que deveria ocorrer no fim das apresentações. Os participantes, registram no chat essa insatisfação em torno da falta de diálogo com a audiência, embora tenham reconhecido a importância da fala dos integrantes da mesa, destacando que o debate e a interação com o público teriam contribuído com o processo de formação desses sujeitos. Tal fato pode ser ilustrado na fala do participante 1: "Sinto falta dos debates... ainda temos muito que aprender sobre a garantia do espaço dos diálogos nas nossas discussões acadêmicas".

Essas dificuldades de monitorar o tempo e mediar as discussões, pode estar associada a questões de letramento digital, já evidenciadas na pesquisa realizada pela Superintendência de Educação a Distância (SEAD) da UFBA (UFBA, 2020b). A pesquisa teve como objetivo realizar um diagnóstico institucional sobre as competências digitais para o ensino-aprendizagem dos professores da instituição. Os resultados parciais obtidos a partir da participação de 1.399 professores da UFBA (49\%) ressaltam que $6 \%$ dos professores respondentes não usam as tecnologias digitais em sua prática pedagógica; os professores acima de 60 anos são os que possuem mais dificuldades em interagir com diferentes plataformas digitais; e as professores mulheres apresentaram maiores competência com recursos digitais.

No que se refere a interação dos participantes nas lives analisadas, realizamos a classificação dos comentários do chat ao vivo com base nas seguintes categorias apresentadas na seção anterior. Os dados foram sistematizados e podem ser observados na Figura 1. 
Figura 1 - Categorização dos comentários das lives analisadas

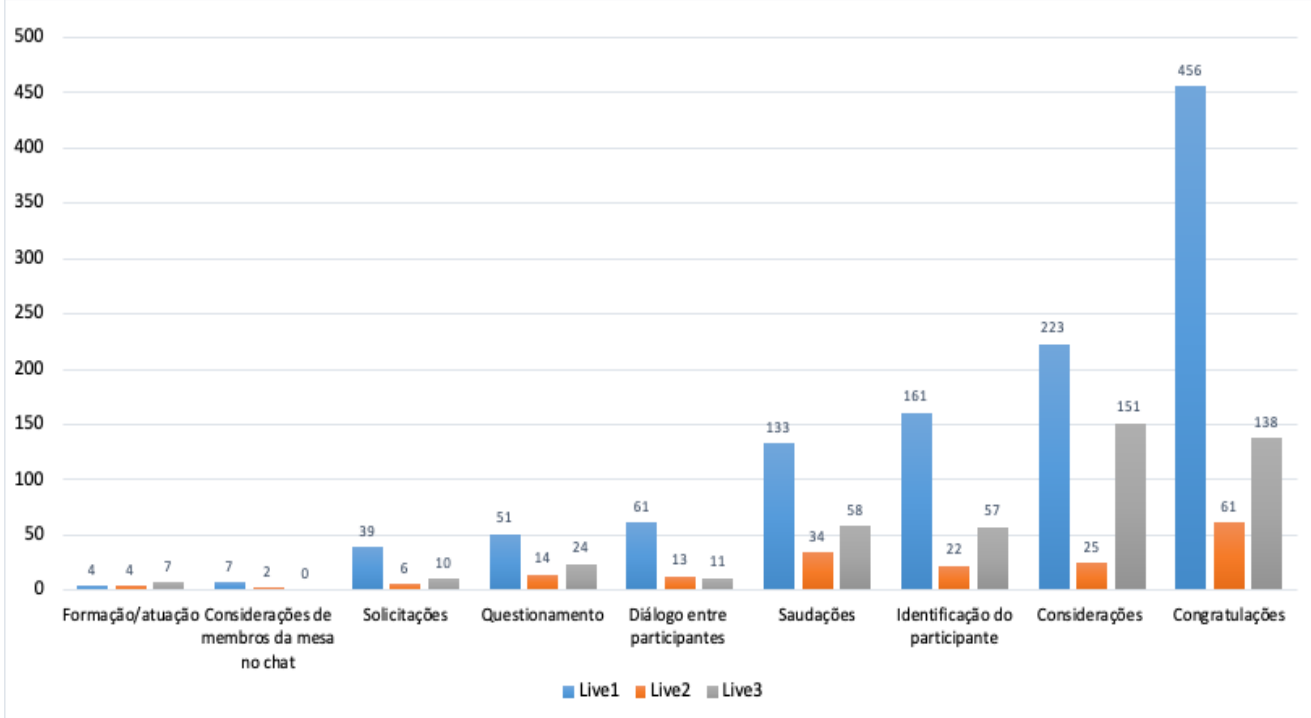

Fonte: Elaboração própria.

No que se refere a interação no chat, a Figura 1 indica uma predominância de comentários com congratulações dos participantes ouvintes aos integrantes da mesa. Essas congratulações estão muitas vezes associadas a euforia dos participantes em relação a alguns palestrantes que, em muitos casos, são grandes ícones acadêmicos, pesquisadores e cientistas prestigiados.

Acreditamos que as congratulações realizadas pelos participantes durante as lives, que evidenciaram um maior quantitativo na forma de se comunicar, pode estar relacionado com a nossa necessidade de pertencer e fazer parte de um grupo. Para Gastal e Pilati (2016, p. 286) “A necessidade de pertencimento individual influencia como o sujeito percebe e se comporta no meio social. A valorização da aceitação e a necessidade de estabelecer laços tornam os indivíduos mais bem adaptados para operar no meio social".

0 atual reitor da UFBA, o professor José Carlos Sales, sempre destaca em suas falas a importância da "patiologia"4. Segundo ele, este termo era amplamente utilizado pelos seus colegas da Faculdade de Filosofia, para designar o espaço de interação em que, professores e alunos dialogavam, se socializavam e discutiam abertamente. Nesses espaços, o laço de autoridade e o distanciamento, muitas vezes estabelecidos em sala de aula, eram quebrados.

Este fenômeno foi identificado nas lives analisadas neste artigo e pode estar associado ao cenário de distanciamento físico e social devido a pandemia do Coronavírus, já que os sujeitos buscam delinear laços sociais, positivos e recompensadores, que podem sinalizar a sua aceitação pelo outro,

4 Ver exemplo da fala do reitor, na live realizada no Instagram no perfil “UFBA Sincero", no dia 15/04/2020. Disponível em: https://www.instagram.com/tv/CAOdETpAhaK/?igshid=phb244h6gc2f. 
contribuindo para o equilíbrio da sua saúde mental. Destacando assim, a necessidade de manterem as regras de sociabilidade presentes nos encontros presenciais.

Outro ponto que destacamos é a necessidade de se tornar visível para aquele que ocupa um lugar, seja como referência teórica, docente e/ou de vínculo de amizade. Assim, podemos supor que o distanciamento físico e social, tem colaborado para manifestações mais afetivas e eufóricas por parte da comunidade que participa das lives e desejam se sentirem mais próximos dos seus pares.

Além disso, os dados da Figura 1 indicam que na live 3, nenhum participante da mesa interagiu no chat. Já nas lives 1 e 2 que tiveram, respectivamente, 7 e 2 considerações de membros da mesa no chat, ambas foram realizadas pelo mesmo professor. Essa interação limitada com o público pode estar associada a questões de letramento digital desses professores, que possuem dificuldade em interagir com diferentes recursos digitais simultaneamente.

Um outro fenômeno observado é a repetição de comentários no chat ao vivo das lives. Por exemplo, uma participante da live 1 insistiu em uma pergunta que não teve resposta. A questão era: "Queria ouvir de Nelson e Edmea o que eles poderiam dizer sobre robôs corrigindo provas". Acreditamos que essa necessidade de ter um posicionamento dos professores que são investigadores da área de educação e tecnologia, estava relacionada com a notícia sobre a utilização de robôs para corrigir os textos dos alunos, pela Rede Laureate, sem conhecimento dos sujeitos (DOMENICI, 2020).

A análise realizada aponta a dificuldade de os professores dialogarem com o modelo de lives, considerando as especificidades das plataformas e necessidade de interatividade dos participantes que desejam interagir com os palestrantes de forma mais efetiva. Tal dinâmica torna-se desafiante já que as atividades realizadas on-line, tiveram um público, com mais de 100 pessoas, com demandas de informação diferenciadas.

As lives analisadas, como dito antes, evidenciaram: a) o desejo dos participantes de se tornarem visíveis para àqueles que respeitam e admiram; b) o fortalecimento do sentimento de pertencer a um grupo; c) a necessidade de manterem as regras de sociabilidade presentes nos encontros presenciais. Tais indicadores se distanciaram do caráter mais formativo das lives que discutiram temas que estão na ordem do dia, devido às restrições provocadas pela pandemia, a exemplo: educação a distância, educação remota e/ou homeschooling. Contudo, acreditamos que o registro destes encontros poderá no futuro próximo, fomentar discussões que poderão contribuir para reflexões e práticas mais formativas no que se refere ao fazer docente.

Ressaltamos, ainda que apesar do quantitativo reduzido de questionamentos, quando comparado com as congratulações, esse número ainda evidencia o engajamento dos sujeitos a se envolverem em projetos como os apresentados pela Rede Educa Nordeste na live 2. 0 diálogo no chat entre os participantes 3 e 4 ilustra essa manifestação, bem como a interação, apoio e orientação entre a audiência.

Participante 3: Eu queria fazer divulgação científica nas escolas públicas.

Participante 4: Que maravilha, @Participante3! Se candidata como voluntária em alguma das escolas da Rede EDUCA NE.

Participante 3: Oi @Participante4, será que ex alunos da UFBA podem participar?

Participante 4: @Participante3, entre em contato com o pessoal da UFBA. Talvez a Profa. Andreia Oliveira. É que sou do IFBA e estou em parceria no Rede EDUCA NE. 
Os dados também indicam que a Live 1: "Formação de professores, educação online e democratização do acesso às redes”, aponta quantitativamente um número maior de interação nas categorias analisadas, não apenas por ter um número maior de participantes, mas por ter palestrantes que têm uma inserção na discussão dos temas que tencionam a relação entre educação e tecnologia. Aqui também vemos o diálogo entre os participantes, o que se constitui em um aspecto positivo, na medida em que todos têm um saber e algo para compartilhar. Tal fato pode ser ilustrado no seguinte exemplo: Muito desafiador e necessário repensar a formação com essa perspectiva do acontecimento, e da experiência! 0 trabalho coletivo é fundante, para que a formação não seja apenas abstração (PARTICIPANTE 5).

Assim, é possível que os processos de interação entre os palestrantes e audiência das lives que discutiram educação, tecnologia e pandemia, possam no futuro, subsidiar novas reflexões e práticas dos participantes, já que a análise dos comentários durante a realização do evento, não nos permite concluir a efetiva contribuição das atuações dos palestrantes e participantes para ir além do prazer de estar juntos mesmo distantes. Contudo, seria necessária uma investigação mais longitudinal para avaliar de que forma esse processo iniciado nestas plataformas, agregaram mudanças significativas ao fazer pedagógico dos docentes presentes nas lives.

\section{CONSIDERAÇ̃̃ES FINAIS}

As lives vêm se apresentando como espaços de entretenimento, interação e informação. Contudo, a nossa participação seja nas lives analisadas e/ou em outras escolhidas por objetivos distintos, apontam que para além da empolgação do momento e/ou obrigações exigidas profissionalmente, pouco avançamos na discussão que está em pauta, especialmente naquelas que se propõem a debater temas que tensionam os sistemas educacionais, tanto na educação básica quanto na superior.

Assim, as provocações efetivadas nas mesas que analisamos podem despertar o interesse da audiência pela busca de novas informações para compreender a construção de uma prática na qual teremos restrições de contato social, de acesso as plataformas digitais conectadas à internet, de retorno imediato as questões que nos afligem e gostaríamos de dialogar e ouvir o posicionamento daqueles que ocupam o lugar academicamente diferenciado.

No que se refere ao fenômeno que analisamos acima, podemos concluir que a interatividade tão desejada ficou comprometida pela quantidade de pessoas conectadas e pelas dificuldades dos docentes/ palestrantes de lidar em muitos momentos, especialmente aqueles com pouco experiência nas plataformas de streaming, com diferentes canais de comunicação (chat, redes sociais, entre outros simultaneamente), sem ter o retorno tão importante que marca as nossas atividades presenciais: o face-to-face.

Sim, temos que aprender a imergir nesse novo universo e nos apropriar, criando um canal para efetivar as estratégias de ensino aprendizagem, inclusive na formação docente, mediadas por estas plataformas digitais, especialmente por não termos no momento uma certeza de quando voltaremos para os encontros presenciais e a rotina de ensino, pesquisa e extensão vivida antes da pandemia ${ }^{5}$.

50 Conselho Superior de Ensino, Pesquisa e Extensão (CONSEPE), através da resolução n01/2020, aprovou o Calendário Acadêmico do Semestre Letivo Suplementar. Indicando o início das atividades remotas na UFBA para o dia 8 de setembro de 2020. 
Assim, o Congresso UFBA, possibilitou a construção de um rico repositório com temas diferenciados em distintas áreas, com pesquisadores, inclusive internacionais e que podem ser acessados a qualquer momento e em qualquer lugar, contribuindo para a formação daqueles que provocados pelas temáticas, vão em busca de novas informações que podem se transformar em conhecimentos. Mas além disso, se constituiu em um marco na forma de fazer uma universidade em movimento, apesar do distanciamento físico e social.

Desta forma, as lives realizadas por diferentes instituições e segmentos são como oásis no deserto provocado pela pandemia do Coronavírus.

\section{REFERÊNCIAS}

BRASIL. Ministério da Educação. Portaria n 343, de 17 de março de 2020. Brasília-DF, 2020a.

BRASIL. Ministério da Educação. Portaria n 345, de 19 de março de 2020. Brasília-DF, 2020 b.

BRASIL. Ministério da Educação. Portaria n 356, de 20 de março de 2020. Brasília-DF, 2020c.

BRASIL. Ministério da Educação. Portaria n 473, de 12 de maio de 2020. Brasília-DF, 2020 d.

DOMENICI, Thiago. Faculdades da Laureate substituem professores por robô sem que alunos

saibam. 2 de maio de 2020. Disponível na URL: http://twixar.me/f21m. Acesso em: 5 maio 2020.

\section{EDGAR DIGITAL. Congresso Virtual inova, bate recorde de público e marca a história da}

Universidade. 30 de maio de 2020. Disponível em: http://twixar.me/g31m. Acesso em: 1 jun. 2020.

GASTAL, Camila Azevedo; PILATI, Ronaldo. Escala de necessidade de pertencimento: adaptação e evidências de validade. Psico-USF, Bragança Paulista, v. 21, n. 2, p. 285-292, 2016. Disponível em http://twixar.me/931m. Acesso em: 1 jun. 2020.

GERMANO, Felipe. Bombou na quarentena: porque o Zoom é um desastre de privacidade para você. UOL. 2 de abril de 2020. Disponível em http://twixar.me/rC1m. Acesso em: 1 jun. 2020.

OMS - Organização Mundial da Saúde. 0 impacto da pandemia na saúde mental das pessoas já é extremamente preocupante. 14 de maio de 2020. Disponível na URL: http://twixar.me/J31m. Acesso em: 25 maio 2020.

LESKIN, Paige. Instagram Live usage jumped 70\% last month. A psychologist says it's because 'people are not designed to be isolated.' 16 de abril de 2020. Disponível na URL: http://twixar.me/ y31m. Acesso em: 26 maio 2020. 
SILARD, Anthony. How to Survive the Quarantine without Becoming a 'Zoombie'. 21 de abril de 2020. Disponível em: http://twixar.me/z31m. Acesso em: 25 maio 2020.

TV UFBA. A educação no brasil em tempos de pandemia e a defesa da educação pública de qualidade em todos os níveis. Youtube, 2020a. Disponível em: http://twixar.me/S31m. Acesso em: 1 jun. 2020.

TV UFBA. Educação em ciências na Escola no contexto da pandemia: ações da Rede Educa UFBA. Youtube, 2020b. Disponível em: http://twixar.me/X31m. Acesso em: 1jJun. 2020.

TV UFBA. Formação de professores, educação online e democratização do acesso às redes. Youtube, 2020c. Disponível em: http://twixar.me/j31m. Acesso em: 1 jun. 2020.

UFBA, Superintendência de Educação a Distância (SEAD). Aprendizagem online em tempos de Pandemia Covid-19. Estudantes da graduação e pós graduação: Panorama da avaliação preliminar. 2020a. Disponível em: http://twixar.me/SK1m. Acesso em: 1 jun. 2020.

UFBA, Superintendência de Educação a Distância (SEAD). Diagnóstico das competências digitais dos professores da UFBA: panorama da avaliação preliminar. 2020b. Disponível em: http://twixar. me/zK1m. Acesso em: 1 jun. 2020.

VAN DIJCK, José; POELL, Thomas; DE WAAL, Martijn. The platform society: Public values in a connective world. Oxford University Press, 2018. 


\section{(). (1) (-)}

Este artigo é licenciado na modalidade acesso abertosob a Atribuição-Compartilhalgual CC BY-SA

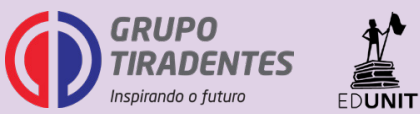

